\title{
Analysis and Evaluation of the Success of City's Smart Growth
}

\author{
Shan Guan ${ }^{1,}$, , Jiaming Zhu ${ }^{2, b}$ \\ ${ }^{1}$ School of Finance, Anhui University of Finance and Economics, Bengbu, 233030, China; \\ ${ }^{2}$ School of Statistics and Applied Mathematics, Anhui University of Finance and Economics, \\ Bengbu, 233030, China \\ a18895675874@163.com, bzhujm1973@163.com
}

\begin{abstract}
Keywords: city smart growth, Lao Shan, evaluation metric system, fuzzy comprehensive evaluation, MATLAB.
\end{abstract}

\begin{abstract}
For urban smart growth in Lao Shan, firstly, this paper selected 12 indictors from four aspects of total urban growth, urban growth intensity, urban growth efficiency and urban growth level to build the evaluation metric system of Lao Shan's smart growth success rate. Then, we defined the differences between new success ratios and original success ratios as the evaluation indexes' potential, and got the growth potential ranking from the most potential to the least. Finally, we provided some directions and suggestions for the future development of Lao Shan based on the analysis and calculation above.
\end{abstract}

\section{Introduction}

The concept of "smart growth" is intended to promote a sense of local belonging, protect natural and cultural resources and develop the community planning, community design and community revitalization with equitable distribution of development costs and benefits. Smart growth can promote long-term ecological integrity and improve the quality of citizen's life through providing a variety of modes of transportation, employment and housing. Smart growth is an efficient, intensive, compact urban development model, which adheres to the three E's. It focuses on economic prosperity, social equality and environmental sustainability.

The world is rapidly urbanizing. It is estimated that urban population will account for $66 \%$ all over the world by 2050 . So it is extremely important to develop plans for urban smart growth, which can ensure that people have social equality and sustainable development of their homes, curb the continued spread of the city and reduce the loss of the surrounding farmland around the city.

\section{Assumptions}

Disasters, wars, or major policy changes have not occurred during the forecast.

The national population and the total resource load keep the basic balance.

Area is a closed system. The region's economy and resources are only used to carry the population within the region.

The selected indicators are independent and do not affect each other.

\section{Evaluation of the success of city's smart growth}

\subsection{Smart Growth Success Rate Evaluation Index System.}

The most representative of the evaluation methods about smart growth was put forward by Wayne University of Galster and the University of Maryland, Hanson and other scholars who made the analysis of the connotation of urban sprawl. The urban growth was assessed by eight categories of indicators: density, continuity, concentration, compactness, centrality, cohesiveness, blending and proximity. These eight indicators were the detailed breakdown of city smart growth involving the population size, land area, employment and other aspects. 


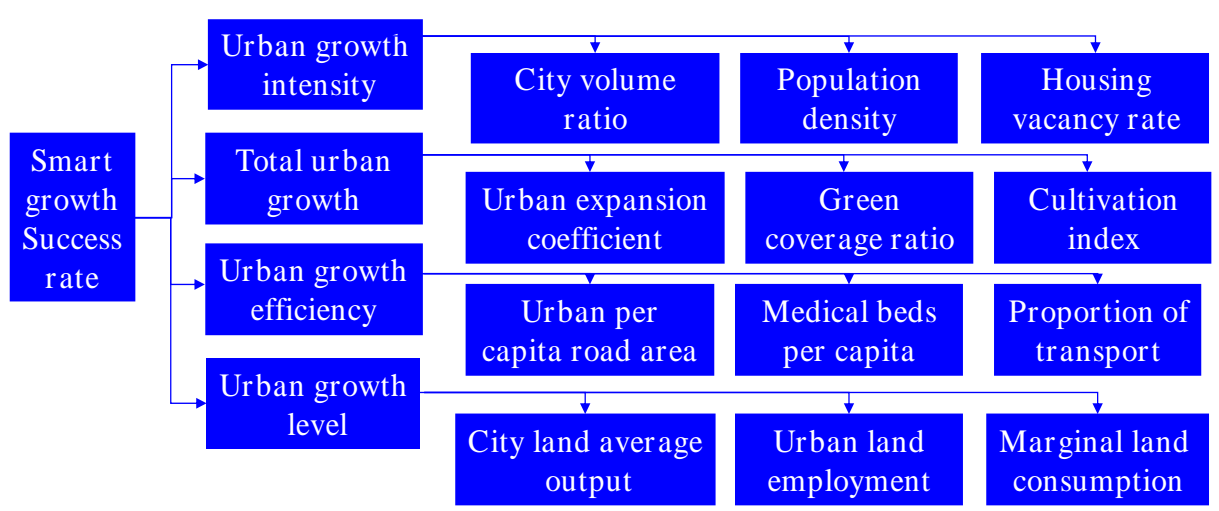

Figure. 1: Smart Growth Success Rate Evaluation Index System.

We've consulted a variety of books about the concept of smart growth. Taking three E's (economic prosperity, social equality and environmental sustainability) principles into account, the index measuring the success rate of urban smart growth was determined by urban growth intensity, total urban growth, urban growth efficiency, urban growth level. Regarding these four aspects as a guideline layer, the urban expansion coefficient, cultivation index, green coverage rate, city volume rate, population density, housing vacancy rate, city land average output, urban land employment, marginal land consumption, urban per capita road area, number of medical beds per capita and proportion of public transport 12 indicators were classified in detail as a program layer.In this way, we built the evaluation index system of urban smart growth success rate shown in Figure 1.

As urban growth itself was a non-static process of change, the relative index of the ratio between the two variables was used in the index design selection. In reference to the relevant literature, we finally identified the smart city growth's impact evaluation indicators based on the availability of data, the completeness of data and the operability of design indexes. The following describes the specific meaning of these indicators.

\section{(1)Urban expansion coefficient}

The urban expansion coefficient is a variable index to measure the total urban growth. It reflects the intensive degree of urban growth. As Gagster's smart growth theory emphasizes the intensive use of urban land resources, the urban expansion coefficient can reflect the change of urban construction land brought about by the urban population growth. The formula is as follows.

$$
K=\frac{\Delta A / A}{\Delta P / P} \text {. }
$$

In this formula, $K$ is the urban expansion coefficient; $A$ is urban built-up area; $P$ is the nonagricultural population. When $K>0$, the transformation between built-up area and non-agricultural population were in the same direction and the built-up area will increase with the growth of nonagricultural population. Otherwise, the result is reverse.

\section{(2)Cultivation index}

Cultivation index refers to the proportion which the cultivated area accounts for of total land area. It is the development and utilization degree of land resources in areas.

The mathematical expression of cultivated index change model is:

$$
\begin{aligned}
\Delta I_{b-a} & =I_{b}-I_{a}=\left\{\frac{\sum a_{i b}-\sum a_{i a}}{A}\right\} \times 100 . \\
d I_{b-a} & =\frac{\Delta I_{b-a}}{I_{a}} \times 100 \times \frac{1}{t} \times 100 \% .
\end{aligned}
$$

In this model, $I_{a}, I_{b}$ respectively represent the cultivation index of analyzed unit in $a$ time and $b$ time. $\Delta I_{b-a}$ Is the change of cultivated index between period $a$ and period $b ; d I_{b-a}$ represents the rate of change in cultivation index corresponding to the time period. $t$ Is the time period of $b-a$.

\section{(3)Green coverage ratio}

Green coverage ratio reflects the degree of urban greening environmental construction and improvement through the growth of the city. The formula is expressed as:

$$
G=S_{g} / A \text {. }
$$


Where $G$ is green coverage ratio; $S_{g}$ is urban greening area; $A$ is the urban built-up area.

\section{(4)City volume ratio}

The city volume ratio indicates the degree of land's development within the urban area. Under normal circumstances, the larger the city volume rate is, the greater the intensity of urban growth will be.

\section{(5)Population density}

Population density is the urban population per area of the city. Expressed as a formula: $I=P / S_{d}$.

In the formula, $I$ is referred to population density. $P$ denotes urban non-agricultural population. $S_{a}$ Represents the urban construction land.

\section{(6)Housing vacancy rate}

Housing vacancy rate refers to the ratio of vacant housing area to total housing area at a certain time.

\section{(7)City land average output}

Urban land productivity is the main criterion to judge the efficiency of urban growth. The higher the total economic output of unit land is, the higher the intensive use of the land will be. The formula of city land average output is as follows:

$P_{d}=E / S_{a}$

Where: $P_{d}$ is referred to the city land average output. $E$ is referred to urban GDP. $S_{a}$ is referred to urban construction land.

\section{(8)Urban land employment}

Ratio of urban employment population to urban construction land is used to represent the unit of land employment level. The formula is expressed as:

$$
P_{W}=W / S_{a}
$$

In this formula, $P_{w}$ is referred to urban land employment. $W$ is referred to employment population. $S_{a}$ is referred to urban construction land.

\section{(9)Marginal land consumption}

Marginal land consumption refers to the amount of money spent on each additional unit of land area.

\section{(10) Urban per capita Road area}

The per capita road area indicates the progress and improvement of urban road construction along with the expansion of the city. It largely determines the efficiency of urban production and life. The formula is expressed as:

$$
S_{r}=S / P_{c} \text {. }
$$

In this formula, $S_{r}$ is referred to urban per capita road area. $S$ is referred to road area. $P_{c}$ is referred to urban population.

\section{(11) Number of medical beds per capita}

The number of medical beds per capita reflects the level of medical and health services and the accessibility of medical facilities in a city. It represents the harmony of urban development from the side. Expressed as a formula:

$$
N_{b}=B / P_{c} \text {. }
$$

In this formula, $N_{b}$ is referred to number of medical beds per capita. $B$ is referred to urban medical beds. $P_{c}$ is referred to urban population.

\section{(12)Proportion of public transport}

The proportion of public transport travel is the main measure on the cities' low consumption of the environment .The formula is as follows:

$$
T=N / P_{c} \text {. }
$$

In this formula, $T$ is referred to proportion of public transport. $N$ is referred to number of standard buses. $P_{c}$ is referred to urban population. 


\subsection{Relative deviation fuzzy matrix evaluation.}

This paper selected a medium-sized city from China-Lao Shan, collected Lao Shan's data on 12 indicators in 2015, and sorted out its development plan in 2016 from its official website and National Development Strategy Report which worked as the basis to analyze the success rate of Lao Shan current development plan.

The advantage of evaluation method of relative deviation fuzzy matrix is that we don't need to preprocess the raw data. The relative deviation matrix is obtained by eliminating the dimension.

Firstly, we defined optimal ideal scheme for urban smart growth.

$x^{0}=\left\{x_{1}^{0}, x_{2}^{0}, \cdots, x_{12}^{0}\right\}=\{8.2,10.4,35 \%, 3,0.06,0.05,5,0.125,0.5,3.2,100,10\}$

Then, we built relative deviation fuzzy matrix:

$$
R=\left(\begin{array}{cccc}
r_{11} & r_{12} & \cdots & r_{1 j} \\
r_{21} & r_{22} & \cdots & r_{2 j} \\
\cdots & \cdots & \cdots & \cdots \\
r_{i 1} & r_{i 2} & \cdots & r_{i j}
\end{array}\right)
$$

Where $r_{i j}=\frac{\left|a_{i j}-x_{j}^{0}\right|}{\max \left\{a_{i j}\right\}-\min \left\{a_{i j}\right\}}(i=1,2 ; j=1,2, \cdots, 12)$.

The evaluation index weights calculated by entropy method are shown in Table 1

Table 1 Urban smart growth metrics' weight in Lao Shan.

\begin{tabular}{|c|c|c|c|c|c|c|c|}
\hline $\begin{array}{c}\text { Second } \\
\text { level index }\end{array}$ & weight & third level index & weight & $\begin{array}{l}\text { Second level } \\
\text { index }\end{array}$ & weight & third level index & weight \\
\hline \multirow{3}{*}{$\begin{array}{l}\text { total urban } \\
\text { growth }\end{array}$} & \multirow{3}{*}{0.1050} & $\begin{array}{c}\text { urbanexpansion } \\
\text { coefficient }\end{array}$ & 0.2530 & \multirow{3}{*}{$\begin{array}{l}\text { urban growth } \\
\text { efficiency }\end{array}$} & \multirow{3}{*}{0.2313} & $\begin{array}{c}\text { City land average } \\
\text { output }\end{array}$ & 0.3909 \\
\hline & & cultivation index & 0.4629 & & & $\begin{array}{l}\text { Urban land } \\
\text { employment }\end{array}$ & 0.3171 \\
\hline & & $\begin{array}{c}\text { green coverage } \\
\text { ratio }\end{array}$ & 0.2842 & & & $\begin{array}{l}\text { Marginal land } \\
\text { consumption }\end{array}$ & .2920 \\
\hline \multirow{3}{*}{$\begin{array}{l}\text { urban } \\
\text { growth } \\
\text { identity }\end{array}$} & \multirow{3}{*}{0.6231} & city volume ratio & 0.3000 & \multirow{3}{*}{$\begin{array}{c}\text { urban growth } \\
\text { level }\end{array}$} & \multirow{3}{*}{0.0405} & $\begin{array}{l}\text { Urban per capita } \\
\text { road area }\end{array}$ & 0.0022 \\
\hline & & $\begin{array}{l}\text { density of } \\
\text { population }\end{array}$ & 0.4329 & & & $\begin{array}{c}\text { Number of } \\
\text { medical beds per } \\
\text { capita }\end{array}$ & 0.7846 \\
\hline & & $\begin{array}{l}\text { housing vacancy } \\
\text { rate }\end{array}$ & 0.2671 & & & $\begin{array}{c}\text { Proportion of } \\
\text { public transport }\end{array}$ & 0.2133 \\
\hline
\end{tabular}

Table 2 Success rate of Lao Shan's current and future plan.

\begin{tabular}{|c|c|c|}
\hline & $\begin{array}{l}\text { Current development } \\
\text { in } 2015\end{array}$ & Growth plan in 2016 \\
\hline urban expansion coefficient & 14.6428 & 9.5412 \\
\hline cultivation index & 0.0253 & 0.056 \\
\hline green coverage ratio & 0.1677 & 0.5000 \\
\hline city volume ratio & 0.0325 & 0.0393 \\
\hline density of population & 0.3588 & 0.3200 \\
\hline housing vacancy rate & 0.2231 & 0.1473 \\
\hline city land average output & 4.2554 & 4.2301 \\
\hline urban land employment & 0.1711 & 0.1527 \\
\hline marginal land consumption & 0.8425 & 0.6954 \\
\hline urban per capita road area & 0.1389 & 0.2986 \\
\hline $\begin{array}{l}\text { number of medical beds per } \\
\text { capita }\end{array}$ & 21.3305 & 26.0000 \\
\hline proportion of public transport & 13.3985 & 12.54612 \\
\hline planned success rate & $22.00 \%$ & $23.46 \%$ \\
\hline
\end{tabular}


Next we built a comprehensive evaluation model, where success rate of the urban development plan was expressed as the degree of deviation between the development plan and the optimal plan. The formula of success rate is:

$$
\begin{aligned}
F_{i} & =\sum_{j=1}^{12} W_{i} r_{i j}(i=1,2), \\
S_{i} & =\left(1-F_{i}\right) \times 100 \%(i=1,2) .
\end{aligned}
$$

Based on the best option, we calculated the success rates of the current and development plan in Lao Shan, $22.00 \%$ in 2015 and $23.46 \%$ in 2016.It can be seen clearly in Table 2 that the success rate in Lao Shan increased smoothly from 2015 to 2016.

\section{The potential of $\mathbf{1 2}$ evaluation indexes}

The most potential smart city growth plan could make the development of city become comprehensive, sustainable and smart, on the basis of maintaining the status quo. Thus can bring considerably economic and environment benefits for cities. There were 12 evaluating metrics in reasonable and suitable smart development plans, and we compared the potential of these 12 metrics and made a ranking from the most potential to the least among them.

We looked up the future development plan of Lao Shan in the coming decades from Lao Shan government website. Taking Lao Shan's present development in 2015 as a benchmark, we changed every metric respectively while kept other metrics unchanged to get 12 new success rates $b_{i}$. Then it was defined the differences between new success ratios and original success ratios as the metric potentials. Each plan's change rate $\left(\varepsilon_{i}\right)$ reflected the deviation degree between future growth plan's success rate $b_{i}$ and present development's success rate $a$.

Define:

$$
\varepsilon_{i}=\frac{b_{i}-a}{a} * 100 \%
$$

To some extent, $\varepsilon_{i}$ could indicate the potential of different individual initiatives in Lao Shan development plans. We had already known that the success rate a of Lao Shan's development plan in 2015 is $22.00 \%$. The success rate $b_{i}$ of Lao Shan was calculated in accordance with the variation of planning metrics in 2015.

$$
b_{i}=\{22.00 \%, 21.07 \%, 25.70 \%, 22.00 \%, 23.44 \%, 21.73 \%, 22.16 \%, 22.13 \%, 22.54 \%, 24.47 \%, 22.11 \%, 21.78 \%\} ;
$$
$\varepsilon_{i}=\{0.00 \%,-4.21 \%, 16.82 \%,-0.02 \%, 6.55 \%,-1.22 \%, 0.75 \%, 0.60 \%, 2.46 \%, 11.23 \%, 0.51 \%,-0.01 \%\}$.

We made the distribution map shown as Figure 2 about the potential of each metric $\varepsilon_{i}$ through MATLAB. Then we made histogram shown as Figure 3 according to the contribution degree that each metric gave to the success rate of urban smart growth.

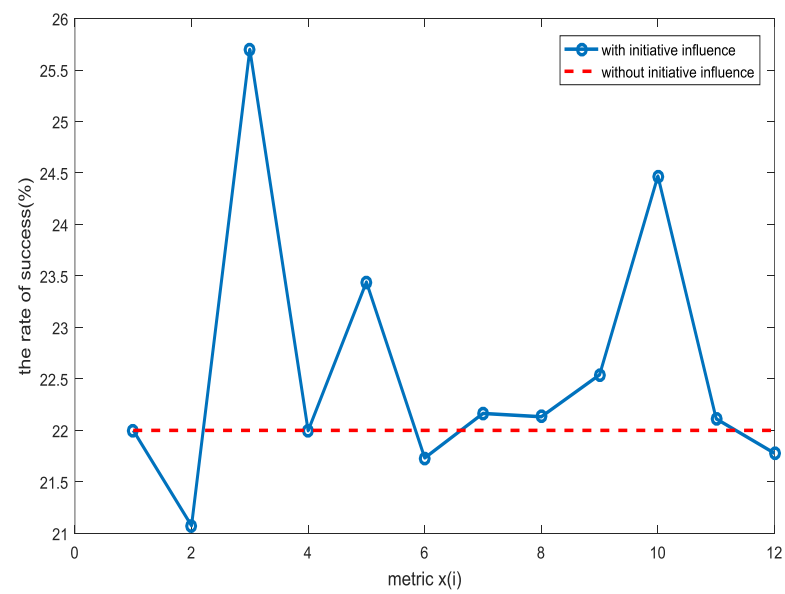

Figure 2 the distribution map of each planning metric in Lao Shan. 


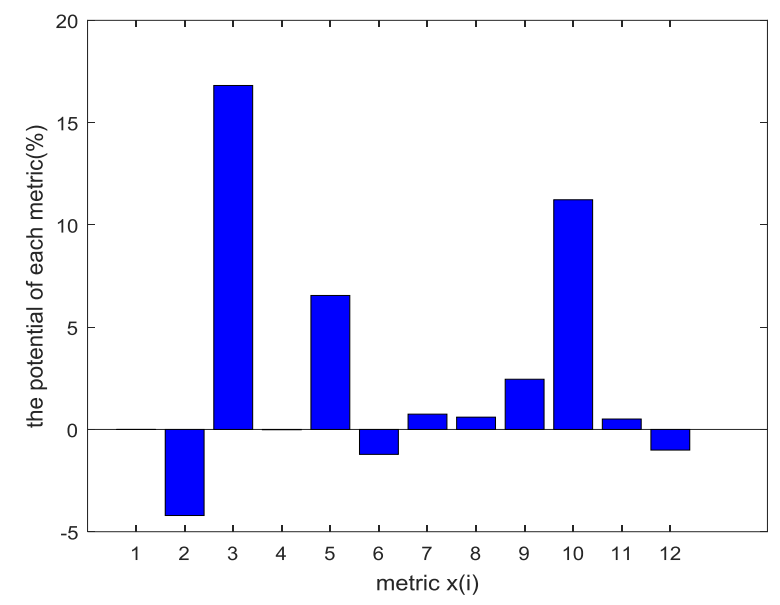

Figure 3 Contribution degree of each planning metric in Lao Shan.

We ranked the individual initiatives within Lao Shan's future smart growth plan based on the value of potential:

$\varepsilon_{3}>\varepsilon_{10}>\varepsilon_{5}>\varepsilon_{9}>\varepsilon_{7}>\varepsilon_{8}>\varepsilon_{11}>\varepsilon_{1}>\varepsilon_{4}>\varepsilon_{12}>\varepsilon_{6}>\varepsilon_{2}$.

Therefore, results from the most potential ranking to the least were: green coverage ratio, urban per capita road area, density of population, marginal land consumption, city land average output, urban land employment, number of medical beds per capita, urban expansion coefficient, city volume ratio, proportion of public transport, housing vacancy rate and cultivation index.

\section{Conclusion}

Based on the analysis and calculation above, we know that green coverage ratio, urban per capita road area and density of population 3 indictors play significant role in making plans for development of Lao Shan's smart growth. In a conclusion, Lao Shan district should pay attention to the protection of the original ecological environment, and promote planting trees to improve green coverage. What's more, according to the design principle of maximizing road area, local government is supposed to extend per capita road area and create more housing opportunities and choices. Due to an increasing number of people in Lao Shan, it is necessary for government to control the speed of population growth in Lao Shan, increasing happiness and harmonious life experience for residents.

\section{References}

[1]. Duany, Andres, Jeff Speck, and Mike Lydon. The smart growth manual. McGraw Hill Professional, 2004.

[2]. Goffman, Ethan. "The Smart Growth Manual." Sustainability: Science, Practice, \& Policy $7.2,2011$.

[3]. Jing Guan. "Research on the smart Growth of Chinese megacity".Jilin University,2013.

[4]. MacLeod, Gordon. "New urbanism/smart growth in the Scottish Highlands: Mobile policies and post-politics in local development planning." Urban Studies ,0042098013491164, 2013.

[5]. P. H. Zhang, L.P. Wang, X.B.Jin, G. Song, Y.K. Zhou, X.1. Yang. "Simulation of Spatiotemporal Dynamical Change of Urban Growth Based onMulti-Agent System: Case Study of Lianyungang City, China”. Scientia Geographica Sinica,vol.11, pp.1289-1296,2012.

[6]. Nicholas, James C., and Ruth L. Steiner. "Growth management and smart growth in Florida." Wake Forest L. Rev. vol.35,PP.645,2000.

[7]. Saaty, Thomas L. "Decision making with the analytic hierarchy process." International journal of services sciences no.1.1,pp.83-98,2008. 
[8]. Saaty, Thomas L. "Analytic hierarchy process." Encyclopedia of operations research and management science. Springer US, pp. 52-64, 2013.

[9]. J. Tan, X. M. Tao, X. Chen. "Comprehensive evaluation of urban smart growth based on improved entropy method". Resources and Environment in the Yangtze Basin, pp.129-136, 2012.

[10]. Z. Z. Hong, Y. Yi, J.N. Sun. "Entropy method for determination of weight of evaluating indicators in fuzzy synthetic evaluation for water quality assessment." Journal of Environmental Sciences vol.18.5,pp.1020-1023,2006

[11]. Kutner, Michael H., Chris Nachtsheim, and John Neter. Applied linear regression models. McGraw-Hill/Irwin, 2004.

[12]. T.H. Huang, R. 1. Liu, A. R. Dang. "Research on smart cites of europe". Design Community,vol.06,PP.129-133, 2011.

[13]. D. Zhang. "The study of city moderate population upon the background of sustainable development". Southwest Jiaotong University,2011.

[14]. Asai, H. Tanaka-S. Uegima-K. "Linear regression analysis with fuzzy model."IEEE Trans. Systems Man Cybern vol.12, pp. 903-907,1982.

[15]. Neter, John, et al. Applied linear statistical models. Vol. 4. Chicago: Irwin, 1996.

[16]. Stiglitz, Joseph. "Growth with exhaustible natural resources: efficient and optimal growth paths." The review of economic studies, vol.41, pp. 123-137, 1974. 